\title{
Association between prenatal exposure to perfluoroalkyl substances and asthma in 5- year-old children in the Odense Child Cohort
}

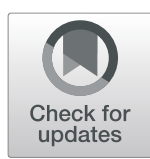

Iben Have Beck', Clara Amalie Gade Timmermann', Flemming Nielsen', Greet Schoeters ${ }^{1,2,3}$, Camilla Jøhnk1, Henriette Boye Kyhl ${ }^{4,5}$, Arne Høst ${ }^{5}$ and Tina Kold Jensen ${ }^{1,4,5^{*}}$

\begin{abstract}
Background: Asthma is the most common non-communicable disease in children. Prenatal exposure to perfluoroalkyl substances (PFASs), a group of persistent environmental chemicals with endocrine disrupting abilities, has been associated with immunomodulation and may contribute to the aetiology of asthma. We investigated the associations between prenatal exposure to five PFASs and asthma in 5-year-old children.

Methods: We studied 981 mother-child pairs within the Odense Child Cohort (OCC), Denmark. We measured perfluorooctane sulfonic acid (PFOS), perfluorooctanoic acid (PFOA), perfluorohexane sulfonic acid (PFHxS), perfluorononanoic acid (PFNA) and perfluorodecanoic acid (PFDA) in maternal serum donated in early pregnancy. A standardized questionnaire based on the International Study of Asthma and Allergies in Childhood (ISAAC) was used to assess wheeze, self-reported asthma and doctor-diagnosed asthma among children at age 5 years. Associations were examined using logistic regression analyses adjusting for parity, maternal educational level, maternal pre-pregnancy BMI, asthma predisposition and child sex.

Results: Among the 5-year-old children 18.6\% reported wheeze and $7.1 \%$ reported asthma. We found no association between prenatal exposure to PFAS and doctor-diagnosed asthma or wheeze. Prenatal PFAS exposure was associated with self-reported asthma, although only significant for PFNA (OR $=1.84,95 \% \mathrm{Cl} 1.03,3.23)$.

Conclusion: Our findings support the suggested immunomodulatory effects of PFASs, however, additional studies are warranted. In order to verify our findings, it is important to re-examine the children with postnatal measurements of serum PFAS concentrations and additional clinical diagnostic testing at an older age where an asthma diagnosis is more valid.
\end{abstract}

Keywords: Perfluoroalkyl substances, PFAS, Prenatal exposure, Asthma, The Odense Child Cohort, Preschool, Children

\section{Background}

Asthma is the most common non-communicable disease in children [1]. The prevalence of asthma in Danish 5-year-old children is estimated to be $12 \%$ [2], it is, however, difficult to verify asthma among preschool children [3, 4]. Asthma diagnosis covers a variety of diseases with similar presentations [5] e.g. recurrent airway obstruction, inflammation of the

\footnotetext{
* Correspondence: tkjensen@health.sdu.dk

${ }^{1}$ Department of Environmental Medicine, Institute of Public Health, University of Southern Denmark, Odense, Denmark

${ }^{4}$ Odense Patient data Explorative Network (OPEN), Odense, Denmark

Full list of author information is available at the end of the article
}

airways and bronchial hyper-responsiveness to different stimuli [6].

Perfluoroalkyl substances (PFASs) are persistent chemicals with long elimination half-lives of 4 to 8 years in humans [7]. They are widely used in the industrial and commercial production of water-resistant fabrics, grease proof materials and non-stick coatings [8, 9]. Humans are exposed to these substances through ingestion of contaminated food and drinking water as well as inhalation of indoor air particles [10-12]. PFASs circulates through the placenta exposing the foetus [13, 14], and some PFASs are detectable in almost all human serumsamples [9, 15]. Perfluorooctane sulfonic acid (PFOS)

C The Author(s). 2019 Open Access This article is distributed under the terms of the Creative Commons Attribution 4.0 International License (http://creativecommons.org/licenses/by/4.0/), which permits unrestricted use, distribution, and 
and perfluorooctanoic acid (PFOA) are the oldest and most investigated PFASs [16].

Their adverse health effects have been documented and they have more or less been phased out from most industries, leading to declining serum concentrations $[17,18]$. For other long-chain PFASs including perfluorohexane sulfonic acid (PFHxS), perfluorononanoic acid (PFNA), and perfluorodecanoic acid (PFDA) phase-out has not been adequately implemented and serum concentrations are increasing in some countries [19]. Previous epidemiological studies have reported associations between prenatal PFAS exposure and immune-related findings e.g. lower antibody responses to childhood immunizations in 5 and 7-year-old children [20]. Thus, PFASs have the ability to modulate the immune system, especially during vulnerable periods of foetal development [21] and could thereby contribute to the aetiology of asthma.

Few studies have investigated the association between prenatal PFASs exposure and asthma or asthma symptoms in children and findings are inconsistent [22-26]. None of the previous conducted studies reported significant associations between prenatal PFAS exposure and doctor-diagnosed asthma, while some found prenatal PFAS exposure to be associated with wheeze [22, 23]. Among these studies, population sizes vary from 99 to 1558 participants and children are between 1 and 10 years of age when assessed. Due to the sparse amount of research conducted in this field, dissimilarities in study settings may play a role in the differing findings.

We therefore seek to contribute and strengthen the evidence within this field of environmental science by investigating the association between prenatal exposure to five PFASs and wheeze, self-reported asthma and doctor-diagnosed asthma among 981, 5-year-old children in the Odense Child Cohort (OCC).

\section{Materials and methods}

\section{Study population and setting}

The OCC is an ongoing prospective cohort study. The cohort participants were recruited during the period 2010 to 2012 by inviting all newly pregnant women $(n=$ 6707) residing in Odense Municipality to participate. Of the eligible women who met the inclusion criteria 2874 (43\%) agreed to participate [27]. At the time of inclusion, a blood sample was drawn, and the participants filled out a questionnaire on their general health, lifestyle and social factors. Information on maternal educational level, smoking status during pregnancy, and pre-pregnancy body mass index, $\mathrm{kg} / \mathrm{m}^{2}$ (BMI) was obtained from the questionnaire. Maternal educational level was categorized into 3 groups; lower (high school or less), intermediate (high school $+1-4$ years of education) and higher (high school + more than 4 years of education).
Information on maternal age, parity (nulliparous or multiparous), and child sex, birth weight and gestational age (GA) were derived from the birth record. Information regarding duration of breastfeeding was obtained from questionnaires completed at 3 and 18 months. During the study period the drop-out was minimal (4\%) and there are currently 2549-registered mother-child pairs (March 2018).

\section{PFAS analysis}

Maternal serum donated at inclusion (GA week 8-16) was analysed for PFAS concentrations in 1628 samples. Analyses included the following compounds; PFOS, PFOA, PFHxS, PFNA and PFDA. Initially a subset of 649 samples were analysed, of these, 200 were selected randomly [28], while the rest were selected based on availability of information from questionnaires, birth records and clinical three-months examinations of the child [29]. Finally, the remaining 979 samples were analysed in January 2019. Until analysis the samples were stored at $-80^{\circ} \mathrm{C}$. PFAS concentrations were estimated using on-line solid phase extraction followed by liquid chromatography and triple quadrupole mass spectrometry (LC-MS/MS) at the Department of Environmental Medicine, University of Southern Denmark. The initial analyses were performed between September 2011 and September 2013 and the remaining in 2019. The withinbatch coefficients of variation (CVs) were $<3 \%$ and the between batch CVs for all sets analysed were $<10.5 \%$. Quality control and quality assessment were based on certified reference material (NIST1958) from the National Institute of Standards and Technology [28]. The limit of quantification (LOQ) was $0.03 \mathrm{ng} / \mathrm{ml}$ for all compounds. PFOS, PFOA, PFNA and PFDA were detected in all samples in this study (LOQ $>0.03 \mathrm{ng} / \mathrm{ml}$ ), while $0.5 \%(5 / 981)$ of the included women had a PFHxS concentration below the LOQ. These 5 were reported as $\mathrm{LOQ} / 2$.

\section{Assessment of asthma}

A modified Danish version of the standardized questionnaire developed by the International Study of Asthma and Allergies in Childhood (ISAAC) [30, 31] completed by parents at child age 5 years, was used for asthma assessment. We selected three outcomes associated with asthma; wheeze, self-reported asthma and doctor-diagnosed asthma. Wheeze was assessed by the question "Has the child experienced whistling or wheezing (asthmatic) respiration at any time since the age of 3 years?". If the parents confirmed, they were asked how many episodes of wheezing the child had experienced within the last 12 months. Self-reported asthma was defined as at least 3 episodes of wheezing (each lasting more than a day), during the past 12 months. Doctor-diagnosed asthma was defined by a positive answer to the question "Does the child have doctor-diagnosed 
asthma?". Children whose parents indicated that the child had not experienced any wheezing episodes and did not answer the next questions regarding self-reported and doctor-diagnosed asthma, were assumed not to have asthma. When parents reported both doctor-diagnosed asthma and self-reported asthma in a child, the child was categorized only as doctor-diagnosed with asthma. Data concerning family history of asthma, concomitant dermatitis or rhinitis, smoking in the household and living with pet(s) were derived from the same questionnaire completed when the child was 5 years [31].

\section{Statistical analyses}

Differences in serum PFAS concentrations among study participants and excluded participants and among the study participants with and without asthma or wheeze were assessed according to child, maternal and upbringing characteristics using Mann-Whitney and Kruskal-Wallis tests. Maternal, birth and child characteristics among mother-child pairs reporting to have or not have wheeze, self-reported asthma and doctor-diagnosed asthma were compared using Chi2-test and Mann-Whitney tests.

Logistic regression models were used to analyse the association between PFAS exposures and asthma. As PFASs distributions were positively skewed, all PFASs concentrations were converted using natural logarithm (ln) in order not to violate model assumptions, and estimates as well as $95 \%$ confidence intervals (CI) from the models were back transformed to express the odds ratios (ORs) of respiratory health outcomes (wheeze, selfreported asthma and doctor-diagnosed asthma) associated with a doubling of maternal PFASs. Potential confounders were identified through directed acyclic graphs (DAG) using Dagity software. Through the DAG we detected parity, maternal educational level, maternal pre-pregnancy BMI as confounders (Additional file 1). Furthermore, asthma predisposition and child sex are strong predictors of childhood asthma and they were therefore included in the models to reduce imprecision. In the final model we adjusted for parity, maternal educational level, maternal pre-pregnancy BMI, asthma predisposition and child sex. We also tested whether the associations were modified by sex by inserting interaction terms (PFAS*child sex) in the logistic regression models. Hosmer-Lemeshow goodnessof-fit test was used for testing the robustness of the logistic regression models.

Results with $p$-values $<0.05$ were considered statistically significant. Statistical analyses were conducted using the statistical program STATA version 14 .

\section{Results}

A total of 2448 singleton mother-child pairs are currently active in the OCC. Of these 1618 responded to the ISAAC based questionnaire at child age 5 years and
PFAS concentrations were analysed in 1617 maternal serum samples. A total of 981 mother-child pairs had answered both the ISAAC questionnaire and had serum PFASs measured (Fig. 1). Included participants reported longer duration of breastfeeding and had higher PFOS concentrations compared to the excluded women (median $7.73 \mathrm{ng} / \mathrm{ml}$ vs. $7.26 \mathrm{ng} / \mathrm{ml}$ ) (data not shown). No differences between excluded and included participants in respiratory outcomes (wheeze, self-reported asthma or doctor-diagnosed asthma) or remaining covariates were found.

Of the 981 participating children, $52.1 \%$ were boys, the mean (SD) birth weight was 3533 (515) grams, and 3.8\% were born preterm ( $<37$ weeks). The mean (SD) duration of breastfeeding was 32.5 (20.3) weeks, mean (SD) maternal age 30.9 (4.3) years, mean (SD) pre-pregnancy BMI was $24.3(4.4) \mathrm{kg} / \mathrm{m}^{2}, 57.6 \%$ of the women were nulliparous, $4 \%$ smoked during pregnancy and $23.1 \%$ had completed a higher education. From the age of 3 to 5 years, $18.6 \%$ of the children had experienced wheeze ( $n=182), 7.1 \%$ had asthma $(n=69)$ of which $4.5 \%$ were doctor-diagnosed asthma $(n=44)$. Children with asthma or wheeze were more likely to have concomitant atopic dermatitis and to have a parent diagnosed with asthma. Their mothers tended to be younger, more overweight and with lower educational level (Table 1). Significantly more boys than girls had wheeze or doctor-diagnosed asthma and significantly more mothers had been smoking during pregnancy among children with doctordiagnosed asthma. Children with self-reported asthma were breastfed for a shorter period and their mothers were more often nulliparous (Table 1).

Higher PFASs concentrations were found in younger, nulliparous women and among women with lower educational level and with lower BMI (Additional file 2). Serum PFAS concentrations differed very little in mothers of children with and without wheeze or doctordiagnosed asthma, but mothers of children with selfreported asthma tended to have higher serum PFAS concentrations (significant for PFNA) (Table 2).

In logistic regression analyses a doubling in PFASs exposure was associated with increased odds of selfreported asthma. After adjustment for parity, maternal educational level, maternal pre-pregnancy BMI, asthma predisposition and child sex, the association remained, although only statistically significant for PFNA (OR = 1.84, 95\% CI 1.03,3.23). No associations between prenatal PFAS exposure and wheeze or doctor-diagnosed asthma were found (Table 3).

Significant interactions between PFOS and sex were found in relation to self-reported asthma and between PFHxS and sex in relation to doctor-diagnosed asthma, thus, the analyses were stratified. After stratification, the only significant ORs were between PFHxS and doctor- 


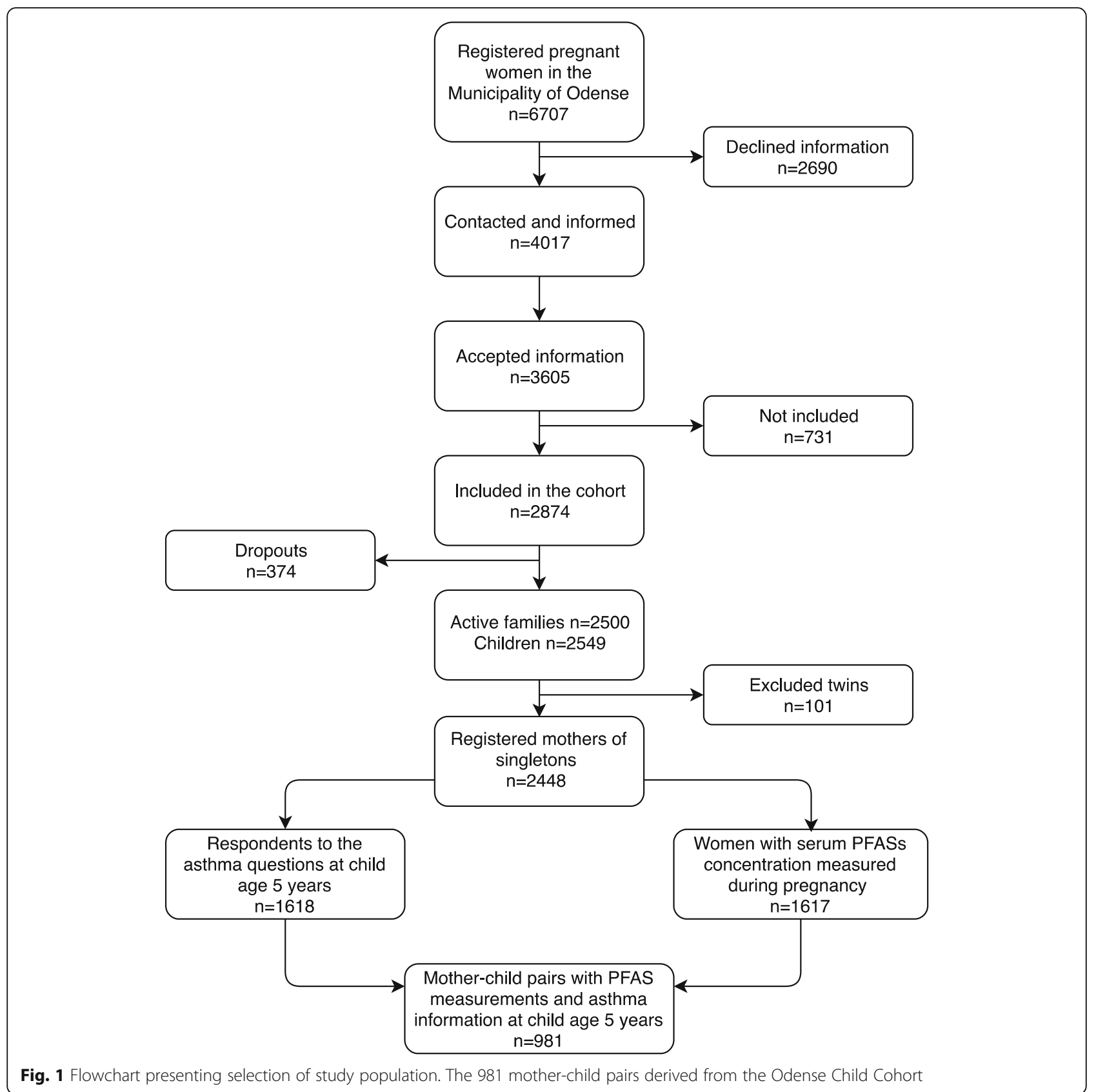

diagnosed asthma in girls and between PFOA and selfreported asthma in boys. In the latter, the interaction was not statistically significant for a difference between sexes and there was no association in the combined (boys and girls) model. The association between prenatal exposure to PFAS and doctor-diagnosed asthma, tended to be stronger in girls, statistically significant for PFHxS $(\mathrm{OR}=2.96$ (95\% CI 1.26,6.96) (Table 3$)$. However only 6 girls had doctor-diagnosed asthma at age 5 years. Opposite tendencies were detected in associations between prenatal exposure to PFAS and self-reported asthma, where a doubling in PFOS, PFOA and PFNA exposure was associated with a doubling in risk of self-reported asthma in boys statistically significant in PFOA (OR = 2.17 (95\% CI 1.07,4.42). The associations between prenatal exposure to PFAS and wheeze virtually remained unchanged after stratification by sex (Table 3).

\section{Discussion}

In this prospective cohort study among 981 motherchild pairs, we found higher ORs for self-reported asthma among 5-year-old children prenatally exposed to PFAS although only statistically significant for PFNA exposure. After stratification by sex the associations 
Table 1 Distribution (\%) of asthma related health outcomes in 5-year-old children $(n=981)$ according to child, maternal and upbringing characteristics in the Odense Child Cohort

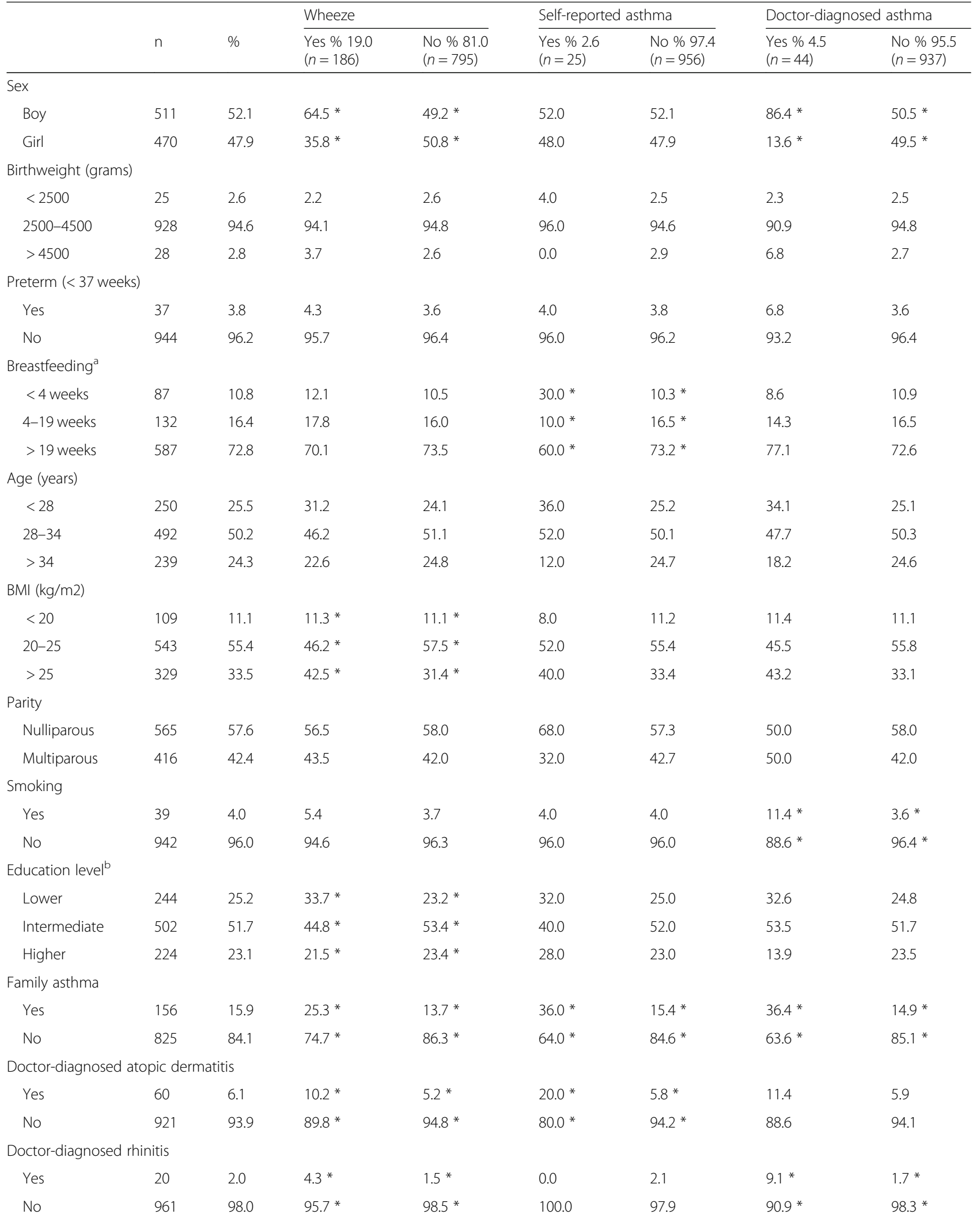


Table 1 Distribution (\%) of asthma related health outcomes in 5-year-old children $(n=981)$ according to child, maternal and upbringing characteristics in the Odense Child Cohort (Continued)

\begin{tabular}{|c|c|c|c|c|c|c|c|c|}
\hline & \multirow[b]{2}{*}{$n$} & \multirow[b]{2}{*}{$\%$} & \multicolumn{2}{|l|}{ Wheeze } & \multicolumn{2}{|c|}{ Self-reported asthma } & \multicolumn{2}{|c|}{ Doctor-diagnosed asthma } \\
\hline & & & $\begin{array}{l}\text { Yes \% } 19.0 \\
(n=186)\end{array}$ & $\begin{array}{l}\text { No \% } 81.0 \\
(n=795)\end{array}$ & $\begin{array}{l}\text { Yes \% } 2.6 \\
(n=25)\end{array}$ & $\begin{array}{l}\text { No \% } 97.4 \\
(n=956)\end{array}$ & $\begin{array}{l}\text { Yes } \% 4.5 \\
(n=44)\end{array}$ & $\begin{array}{l}\text { No } \% 95.5 \\
(n=937)\end{array}$ \\
\hline \multicolumn{9}{|c|}{ Smoking in household } \\
\hline Yes & 141 & 14.4 & 17.2 & 13.7 & 12.0 & 14.4 & 18.2 & 14.2 \\
\hline No & 840 & 85.6 & 82.8 & 86.3 & 88.0 & 85.6 & 81.8 & 85.8 \\
\hline \multicolumn{9}{|c|}{ Pets in household ${ }^{c}$} \\
\hline Indoor & 327 & 35.5 & 41.6 & 33.9 & 40.0 & 35.3 & 47.7 & 34.8 \\
\hline Outdoor & 50 & 5.4 & 4.3 & 5.7 & 4.0 & 5.5 & 2.3 & 5.6 \\
\hline No & 545 & 59.1 & 54.1 & 60.4 & 56.0 & 59.2 & 50.0 & 59.6 \\
\hline
\end{tabular}

a) Missing $(n=175)$. b) Missing $(n=11)$. c) Missing $(n=59)$

${ }^{*} p<0.05\left(\mathrm{Chi}^{2}\right.$ test $)$

between prenatal PFAS exposure and self-reported asthma were stronger in boys, whereas the association between PFAS exposure and doctor-diagnosed asthma were more pronounced in girls. However, only 6 girls had doctor-diagnosed asthma at age 5 years and only two interactions were significant. No significant association between prenatal exposure to PFASs and wheeze at age 5 years was found. The lack of association between prenatal PFAS exposure and wheeze may be due to the fact that young children often experience nonasthmatic wheeze related to common colds, bronchitis or upper respiratoy tract infections [4, 32], and wheeze may be too divergent a diagnosis to detect associations. Also, the children were examined at a young age, where the assessment of asthma is less valid [3]. However, children with doctor-diagnosed asthma as early as the age of 5 years may represent a more severe phenotype more likely to be inherited and therefore less associated to environmental exposures [33] than self-reported asthma. This may explain the lack of association among children with doctor-diagnosed asthma. Boys are more susceptible to childhood asthma than girls [33, 34], and it has been suggested that girls are more susceptible to the immunomodulatory effects of prenatal PFAS exposure
[35, 36], which is consistent with our stratified findings among children with doctor-diagnosed asthma, but not among children with self-reported asthma. The reduced number of cases in each group after stratification yield for cautious interpretation of these findings.

We cannot rule out that our finding have occurred by chance, as no other studies to our knowledge have found significant associations between prenatal PFNA exposure and asthma related outcomes. None of the studies have investigated self-reported asthma as a single health outcome, however, several studies have documented associations between prenatal PFNA exposure and outcomes with infectious origin $[25,37]$ and antibody responsiveness [25] in 0 to 3 -year-old children, indicating that PFNA may have immunomodulatory abilities.

Results from comparable studies are conflicting. A study among 1558 Japanese mother-child pairs from the Hokkaido Cohort found a significant association between prenatal PFHxS exposure and wheeze among 4-year-old children, nonetheless, were found non-significant after covariate adjustment [22]. In the INUENDO cohort, a significant inverse association between prenatal PFOA exposure and wheeze among 5- to 9-year old Ukrainian children was found, whereas no such inverse association was

Table 2 Median maternal serum-PFAS concentrations $(\mathrm{ng} / \mathrm{ml})$ and (25th - 75th percentiles) according to respiratory health outcomes

\begin{tabular}{|c|c|c|c|c|c|c|c|}
\hline \multicolumn{2}{|c|}{$\begin{array}{l}\text { Maternal serum-PFAS concentration } \\
\text { (ng/ml) median (25th-75th percentile) }\end{array}$} & \multicolumn{2}{|l|}{ Wheeze } & \multicolumn{2}{|c|}{ Self-reported Asthma } & \multicolumn{2}{|c|}{ Doctor-diagnosed Asthma } \\
\hline & $\begin{array}{l}\text { All } \\
n=981\end{array}$ & $\begin{array}{l}\text { Yes } \\
n=182\end{array}$ & $\begin{array}{l}\text { No } \\
n=799\end{array}$ & $\begin{array}{l}\text { Yes } \\
n=25\end{array}$ & $\begin{array}{l}\text { No } \\
n=956\end{array}$ & $\begin{array}{l}\text { Yes } \\
n=44\end{array}$ & $\begin{array}{l}\text { No } \\
n=937\end{array}$ \\
\hline PFOS & $7.73(5.68-10.44)$ & $7.69(5.85-10.86)$ & $7.73(5.66-10.39)$ & $8.09(6.90-10.86)$ & $7.72(5.67-10.43)$ & $7.32(5.39-9.01)$ & $7.73(5.70-10.45)$ \\
\hline PFOA & $1.68(1.13-2.35)$ & $1.63(1.17-2.30)$ & $1.69(1.11-2.36)$ & $1.83(1.37-2.59)$ & $1.68(1.12-2.34)$ & $1.55(1.09-1.97)$ & $1.69(1.13-2.37)$ \\
\hline PFHXS & $0.36(0.24-0.50)$ & $0.36(0.25-0.50)$ & $0.36(0.24-0.50)$ & $0.37(0.30-0.48)$ & $0.36(0.24-0.50)$ & $0.34(0.25-0.51)$ & $0.36(0.24-0.50)$ \\
\hline PFNA & $0.65(0.49-0.86)$ & $0.66(0.51-0.86)$ & $0.65(0.49-0.86)$ & $0.75^{*}(0.58-0.96)$ & $0.64^{*}(0.49-0.86)$ & $0.61(0.44-0.77)$ & $0.65(0.49-0.87)$ \\
\hline PFDA & $0.29(0.22-0.40)$ & $0.30(0.22-0.43)$ & $0.29(0.22-0.40)$ & $0.35(0.19-0.46)$ & $0.29(0.22-0.40)$ & $0.29(0.22-0.39)$ & $0.29(0.22-0.40)$ \\
\hline
\end{tabular}

${ }^{*} p<0.05$, using the Mann-Whitney test 
Table 3 Adjusted odds ratio (OR) and 95\% confidence intervals (95\% Cl) for asthma outcomes (wheeze, self-reported and doctordiagnosed asthma) by multiple logistic regression in the 5-year-old offspring for a doubling in maternal serum-PFAS concentrations $(\mathrm{ng} / \mathrm{ml})$. Results also stratified by sex

\begin{tabular}{|c|c|c|c|c|c|c|c|}
\hline \multirow{2}{*}{$\begin{array}{l}\text { All }(n=981) \\
\text { Boys/ Girls } \\
(n=511 / 470)\end{array}$} & \multirow[t]{2}{*}{$n$} & \multicolumn{2}{|c|}{ Wheeze } & \multicolumn{2}{|c|}{ Self-reported asthma } & \multicolumn{2}{|c|}{ Doctor-diagnosed asthma } \\
\hline & & $\bar{n}$ & OR $(95 \% \mathrm{Cl})$ & $\bar{n}$ & OR $(95 \% \mathrm{Cl})$ & $\mathrm{n}$ & OR $(95 \% \mathrm{Cl})$ \\
\hline \multicolumn{8}{|l|}{ PFOS } \\
\hline Unadjusted model & 981 & 182 & $0.99(0.78,1.26)$ & 25 & $1.25(0.68,2.32)$ & 44 & $0.80(0.53,1.23)$ \\
\hline Adjusted model ${ }^{a}$ & 970 & 177 & $1.01(0.79,1.30)$ & 25 & $1.22(0.65,2.28)$ & 43 & $0.83(0.52,1.31)$ \\
\hline Boys $^{b}$ & 507 & 117 & $1.02(0.74,1.39)$ & 13 & $2.39(0.92,6.21)$ & 37 & $0.74(0.46,1.20)$ \\
\hline Girls $^{b}$ & 363 & 560 & $1.01(0.67,1.52)$ & 12 & $0.67(0.29,1.53)$ & 6 & $1.60(0.46,5.59)$ \\
\hline$p^{i}$-value & & & 0.96 & & $0.048^{*}$ & & 0.26 \\
\hline \multicolumn{8}{|l|}{ PFOA } \\
\hline Unadjusted model & 981 & 182 & $1.01(0.83,1.23)$ & 25 & $1.61(0.99,2.63)$ & 44 & $0.84(0.58,1.22)$ \\
\hline Adjusted model $^{a}$ & 970 & 177 & $0.98(0.78,1.23)$ & 25 & $1.57(0.93,2.68)$ & 43 & $0.81(0.53,1.22)$ \\
\hline Boys $^{\mathrm{b}}$ & 507 & 117 & $0.94(0.71,1.23)$ & 13 & $2.17^{*}(1.07,4.42)$ & 37 & $0.72(0.46,1.12)$ \\
\hline Girls $^{b}$ & 363 & 60 & $1.08(0.75,1.55)$ & 12 & $1.06(0.49,2.30)$ & 6 & $1.70(0.63,4.56)$ \\
\hline$p^{i}$-value & & & 0.52 & & 0.17 & & 0.11 \\
\hline \multicolumn{8}{|l|}{ PFHXS } \\
\hline Unadjusted model & 981 & 182 & $1.04(0.87,1.25)$ & 25 & $1.16(0.74,1.84)$ & 44 & $1.02(0.73,1.43)$ \\
\hline Adjusted model ${ }^{a}$ & 970 & 177 & $1.13(0.93,1.38)$ & 25 & $1.18(0.73,1.90)$ & 43 & $1.16(0.78,1.71)$ \\
\hline Boys $^{b}$ & 507 & 117 & $1.03(0.80,1.34)$ & 13 & $1.33(0.66,2.71)$ & 37 & $0.89(0.59,1.34)$ \\
\hline Girls $^{b}$ & 363 & 60 & $1.29(0.94,1.77)$ & 12 & $1.04(0.55,1.98)$ & 6 & $2.96^{*}(1.26,6.96)$ \\
\hline$p^{i}$-value & & & 0.28 & & 0.61 & & $0.013^{*}$ \\
\hline \multicolumn{8}{|l|}{ PFNA } \\
\hline Unadjusted model & 981 & 182 & $1.04(0.81,1.34)$ & 25 & $1.85^{*}(1.06,3.23)$ & 44 & $0.70(0.43,1.13)$ \\
\hline Adjusted model ${ }^{a}$ & 970 & 177 & $1.03(0.79,1.33)$ & 25 & $1.84^{*}(1.03,3.28)$ & 43 & $0.68(0.41,1.14)$ \\
\hline Boys $^{b}$ & 507 & 117 & $0.93(0.67,1.29)$ & 13 & $2.11(0.97,4.58)$ & 37 & $0.58(0.33,1.03)$ \\
\hline Girls $^{b}$ & 363 & 60 & $1.22(0.79,1.87)$ & 12 & $1.50(0.64,3.49)$ & 6 & $1.52(0.47,4.97)$ \\
\hline$p^{i}$-value & & & 0.32 & & 0.56 & & 0.15 \\
\hline \multicolumn{8}{|l|}{ PFDA } \\
\hline Unadjusted model & 981 & 182 & $1.16(0.93,1.44)$ & 25 & $1.37(0.83,2.26)$ & 44 & $0.93(0.61,1.42)$ \\
\hline Adjusted model ${ }^{a}$ & 970 & 177 & $1.16(0.93,1.46)$ & 25 & $1.44(0.87,2.41)$ & 43 & $0.93(0.60,1.44)$ \\
\hline Boys $^{b}$ & 507 & 117 & $1.21(0.92,1.60)$ & 13 & $1.08(0.51,2.29)$ & 37 & $0.91(0.57,1.45)$ \\
\hline Girls $^{b}$ & 363 & 60 & $1.08(0.73,1.58)$ & 12 & $1.88(0.93,3.80)$ & 6 & $1.11(0.38,3.29)$ \\
\hline$p^{i}$-value & & & 0.62 & & 0.28 & & 0.73 \\
\hline
\end{tabular}

a: adjusted for parity, maternal educational level, maternal pre-pregnancy BMI, asthma predisposition and child sex b: adjusted for parity, maternal educational level, maternal pre-pregnancy BMI and asthma predisposition i: $p$-value for PFAS*child sex interaction

*: $p<0.05$

found among the Greenlandic children, who were exposed to PFOA concentrations twice as high as the Ukrainian children [23] (Additional file 3). The OCC children were exposed to lower concentrations of PFAS than children in these cohorts (Additional file 3) which may explain the lack of association in our study. Three other cohort studies [22, 25, 26] with PFAS exposure levels comparable to women in our study found no association between prenatal exposure to PFASs and wheeze, which is consistent with our findings. In addition, we did not find any significant association between prenatal PFAS exposure and doctor-diagnosed asthma, which is consistent with findings from 4 different studies conducted among 1- to 3-year-olds [25] and 2- and 10-year-olds [26] from Norway, 5- to 9-year-olds from Greenland and the Ukraine [23] and among 5-year-olds from the Faroe Islands [24] (Additional file 3). None of these 4 studies conducted sex stratified analyses which 
hinder comparison of our findings indicating sex differences.

Women in this study had lower serum-PFAS concentrations than women from Japan, Greenland and the Faroe Islands [22-24] but higher than women from Norway and the Ukraine [23, 25] (Additional file 3). These differences are consistent with varying PFAS exposure through dietary intake e.g. residents of Japan, Greenland and the Faroe Islands are known to eat more seafood and marine mammals, which are known sources of PFAS exposure [10, 38, 39]. In addition, time trends in PFAS exposure may explain the observed differences. Other discrepancies among study populations, such as geographic areas of residence and diverging definitions of asthma related outcome variables, sizes of study populations and child age, may affect the observed associations in published studies (Additional file 3).

Asthma is characterized by hyper responsiveness to allergens caused by allergen-specific IgE and a shift in the T-helper (Th)-1/Th-2 balance towards Th-2 [21, 40]. Animal models are indicative of immunomodulatory effects after PFASs exposure [41, 42]. Studies in mice report that increasing exposure to PFOS, creates a shift in the cytokine balance toward Th-2, leading to suppression of the cellular response and enhancement of the humoral response [43, 44]. A shift in the cytokine profiles towards Th2, will favour an allergic response $[21,45]$, and prenatal exposure to PFAS may thus contribute in the aetiology of asthma. Toxicological studies provide evidence that exposure to PFOA and PFOS increase the risk for immunomodulation [46]. Studies in mice report associations between PFOS and PFOA exposure and immunomodulatory effects with both prenatal- [47] and concurrent PFAS exposure [41]. Studies investigating concurrent exposure are not directly comparable to studies of prenatal exposure, however, the adverse effects could hypothetically be particular harmful if exposure occur when the immune system is developing in utero. In epidemiological studies, high prenatal exposure to PFASs have been associated with lower antibody responses to childhood immunizations in children aged 3 years [25], 5 and 7 years [20]. Prenatal PFAS exposure have also been associated to childhood infections $[25,26,48]$, supporting the growing evidence of immunomodulatory effects of prenatal exposure to PFAS.

This study has several strengths. It is a large, populationbased, prospective study which secures temporality. Furthermore, we have assessed asthma through international standardized and validated questionnaires [30]. As a measure of prenatal PFASs exposure, we used maternal serum PFAS concentrations collected at GA week 8-16. PFASs can circulate through the placenta and PFAS concentrations in maternal and cord blood are verified highly correlated [13, 14]. Maternal serum concentrations of PFAS are known to decrease throughout pregnancy [17], however, the long half-lives of PFASs reduce the likelihood of large fluctuations in PFASs concentrations during pregnancy [49]. PFASs concentrations measured in early pregnancy are therefore considered reliable to the exposure level during the entire pregnancy.

Women participating in the OCC were older, more often nulliparous and fewer were smokers compared to the background population [27]. This may partially explain the relative low asthma prevalence $(7.1 \%)$ in our study, as both young maternal age and smoking during pregnancy are well known risk factors for asthma in the offspring [50,51]. A Danish study of more than 900,000 Danish 5-year-old children born from 1997 to 2011, reported a $12 \%$ asthma prevalence at age 5 years. The asthma diagnosis was based on hospital contacts and disease-specific dispensed prescribed medications [2], which may overestimate the prevalence. As our population may be healthier than the general population, we cannot rule out the possibility of selection bias, however, we compared women across PFAS exposure, so whether they represented the general population is therefore less important. In addition, participants had no knowledge of their PFAS exposures or asthma symptoms in their child at enrolment. It is therefore unlikely to have affected their participation.

Assessment of asthma in preschool children is challenging and is often based on symptoms and response to medication [3]. To verify the asthma diagnosis diagnostic tests such as spirometry has to be carried out $[3,4]$. These test are not suitable for preschool children, and the diagnosis is therefore less valid for younger children [3]. The worldwide epidemiological research program ISAAC has developed an international, standardized questionnaire [52] by which self-reported asthma can be assessed [30]. Some parents may have misinterpreted recurrent colds or respiratory infection symptoms as asthma [32], and misclassification is therefore likely. However, parents were unaware of their PFAS exposure when responding to the questionnaire, and misclassification is therefore most likely non-differential leading to underestimation of the associations.

We investigated a wide range of potential confounders without notable changes in the estimates, but unmeasured confounding may be present. Recent studies have found that increasing maternal serum-PFAS concentrations reduces the duration of breastfeeding [53, 54]. Breastfeeding is a source of postnatal PFAS exposure for infants $[11,55]$ but has also been associated with reduced risk of childhood asthma [56]. We did not adjust for duration of breastfeeding, as we regarded it to be a mediator (Additional file 1) [57]. A strong association between PFAS exposure and asthma among measles, mumps and rubella (MMR)-unvaccinated children was 
found in a Faroe Island cohort [24], but in the present study only 4 children were known not to be MMR vaccinated, which was not sufficient to test the hypothesis. Previous studies have found childhood serumPFAS concentrations to be associated with childhood asthma [58-60], therefore, as the immune system is developed and matured both pre- and postnatally [40], it will be of relevance to measure serum-PFAS concentrations in the children.

In conclusion, our findings suggest an association between prenatal exposure to PFASs and self-reported asthma in the offspring. We found no significant associations between prenatal exposure to PFASs and doctordiagnosed asthma or wheeze, and additional studies are warranted. Our findings support the reported immunomodulatory effects of PFASs, and are a valuable contribution to research conducted within the public health field. In future studies, it is recommended to analyse the children's serum PFAS concentrations and to re-examine them with e.g. spirometry to validate the asthma diagnosis at a later age.

\section{Supplementary information}

Supplementary information accompanies this paper at https://doi.org/10. 1186/s12940-019-0541-z.

Additional file 1: Figure S1. The causal network between prenatal PFAS levels and asthma, presented in a directed acyclic graph (DAG).

Additional file 2: Table S1. Maternal PFAS concentrations $(\mathrm{ng} / \mathrm{mL})$, median and 25-75 percentiles according to maternal and child characteristics in 981 mother-child pairs in Odense Child Cohort.

Additional file 3: Table S2. Overview of epidemiological cohort studies, investigating associations between prenatal PFASs exposure and respiratory health outcomes in children, Identified through structured PubMed search

\begin{abstract}
Abbreviations
${ }^{\circ} \mathrm{C}$ : degrees Celsius; BMl: Body mass index $\left(\mathrm{kg} / \mathrm{m}^{2}\right)$; Cl: Confidence interval; CV: Coefficients of variation; DAG: Directed acyclic graphs; GA: Gestational age; IgE: Immunoglobulin E; ISAAC: International Study of Asthma and Allergies in Childhood; LC-MS/MS: liquid chromatography and triple quadrupole mass spectrometry; In: Natural logarithm; LOQ: Limit of quantification; ml: millilitre; MMR: measles, mumps and rubella; ng: Nano gram; OCC: Odense Child Cohort; OPEN: Odense Patient data Explorative Network; OR: Odds ratio; PFAS: Perfluoroalkyl substance;

PFDA: Perfluorodecanoic acid; PFHxS: Perfluorohexane sulfonic acid; PFNA: Perfluorononanoic acid; PFOA: Perfluorooctanoic acid;

PFOS: Perfluorooctane sulfonic acid; SD: Standard deviation; Th: T-helper
\end{abstract}

\section{Acknowledgements}

The children and families in the Odense Child Cohort are acknowledged for their participation and commitment to the study. The staff at Hans Christian Andersen's Children's Hospital are acknowledged for their careful examination of the children and the technicians at the Department of Environmental Medicine are acknowledged for the analyses of the PFASs.

\section{Authors' contributions}

The study was designed by TKJ, AH and IHB. IHB analysed the data and drafted the manuscript. CAGT and TKJ contributed to the data analysis and interpretation of data. All authors contributed in drafting and editing the manuscript and have approved the final manuscript.

\section{Funding}

This work was supported by the Danish Council for Independent Research, medical sciences (4004-00352B_FSS and 8020-00123B_FSS), Odense University Hospital and Region of Southern Denmark, Municipality of Odense, the Mental Health Service of the Region of Southern Denmark, Odense University Hospital Research Foundation and Odense Patient data Explorative Network (OPEN), the Novo Nordisk Foundation (NNF150C00017734 and NNF17OC0029404). The University of Southern Denmark's Open Access Fund have covered the publication charges related to Open Access publication.

\section{Availability of data and materials}

The data set used and analysed during the current study are available from the corresponding author on reasonable request.

\section{Ethics approval and consent to participate}

The study was performed in accordance with the Helsinki Declaration II, and approved by the Regional Scientific Ethical Committee for Southern Denmark (Project ID S-20090130).

\section{Consent for publication}

Not applicable.

\section{Competing interests}

The authors declare that they have no competing interests.

\section{Author details}

${ }^{1}$ Department of Environmental Medicine, Institute of Public Health, University of Southern Denmark, Odense, Denmark. '2Environmental Risk and Health Unit, Flemish Institute for Technological Research (VITO), Mol, Belgium. ${ }^{3}$ Department of Biomedical Sciences, University of Antwerp, 2000 Antwerp, Belgium. ${ }^{4}$ Odense Patient data Explorative Network (OPEN), Odense, Denmark. ${ }^{5}$ Hans Christian Andersen Children's Hospital, Odense University Hospital, Odense, Denmark.

Received: 16 May 2019 Accepted: 28 October 2019

Published online: 15 November 2019

\section{References}

1. Asher I, Pearce N. Global burden of asthma among children. Int J Tuberc Lung Dis. 2014;18(11):1269-78.

2. Henriksen L, Simonsen J, Haerskjold A, Linder M, Kieler H, Thomsen SF, Stensballe $L G$. Incidence rates of atopic dermatitis, asthma, and allergic rhinoconjunctivitis in Danish and Swedish children. J Allergy Clin Immunol. 2015;136(2):360-366.e362.

3. Beydon N, Davis SD, Lombardi E, Allen JL, Arets HG, Aurora P, Bisgaard H, Davis GM, Ducharme FM, Eigen H, et al. An official American Thoracic Society/European Respiratory Society statement: pulmonary function testing in preschool children. Am J Respir Crit Care Med. 2007;175(12):1304-45.

4. Hansen S, Hoffmann-Petersen B, Sverrild A, Brauner EV, Lykkegaard J, Bodtger U, Agertoft L, Korshoj L, Backer V. The Danish National Database for asthma: establishing clinical quality indicators. Eur Clin Respir J. 2016;3:33903.

5. Borish L, Culp JA: Asthma: a syndrome composed of heterogeneous diseases. Ann Allergy Asthma Immunol 2008, 101(1):1-8; quiz 8-11, 50.

6. Herzog R, Cunningham-Rundles S. Pediatric asthma: natural history, assessment, and treatment. Mt Sinai J Med. 2011;78(5):645-60.

7. Li Y, Fletcher T, Mucs D, Scott K, Lindh CH, Tallving P, Jakobsson K. Half-lives of PFOS, PFHXS and PFOA after end of exposure to contaminated drinking water. Occup Environ Med. 2018;75(1):46-51.

8. Stahl T MD, Brunn H: Toxicology of perfluorinated compounds. Environmental Sciences Europe - Bridging Science and Regulation at the Regional and European Level 2011.

9. Lassen CJ, A. A.; Potrykus, A.; Christensen, F.; Kjølholt, J.; Jeppesen, C N.; Mikkelsen, S. H.; Innanen, S.: Survey of PFOS, PFOA and other perfluoroalkyl and polyfluoroalkyl substances (part of the LOUS-review). In. Denmark: Danish Ministry of the Environment; 2013.

10. Sunderland EM, Hu XC, Dassuncao C, Tokranov AK, Wagner CC, Allen JG. A review of the pathways of human exposure to poly- and perfluoroalkyl substances (PFASs) and present understanding of health effects. J Expo Sci Environ Epidemiol. 2018. 
11. Bjermo H, Darnerud PO, Pearson M, Barbieri HE, Lindroos AK, Nalsen C, Lindh $\mathrm{CH}$, Jonsson BA, Glynn A. Serum concentrations of perfluorinated alkyl acids and their associations with diet and personal characteristics among Swedish adults. Mol Nutr Food Res. 2013;57(12):2206-15.

12. Trudel D, Horowitz L, Wormuth M, Scheringer M, Cousins IT, Hungerbuhler K. Estimating consumer exposure to PFOS and PFOA. Risk Anal. 2008;28(2):251-69.

13. Gutzkow KB, Haug LS, Thomsen C, Sabaredzovic A, Becher G, Brunborg G. Placental transfer of perfluorinated compounds is selective--a Norwegian mother and child sub-cohort study. Int J Hyg Environ Health. 2012;215(2):216-9.

14. Yang L, Wang Z, Shi Y, Li J, Wang Y, Zhao Y, Wu Y, Cai Z. Human placental transfer of perfluoroalkyl acid precursors: levels and profiles in paired maternal and cord serum. Chemosphere. 2016;144:1631-8.

15. A. JA, B. PP: Survey and environmental/health assessment of fluorinated substances in impregnated consumer products and impregnating agents. In. Edited by Bossi R, No. 99 edn: University of Aarhus, Denmark; 2008: 101-108.

16. Buck RC, Franklin J, Berger U, Conder JM, Cousins IT, de Voogt P, Jensen AA, Kannan K, Mabury SA, van Leeuwen SP. Perfluoroalkyl and polyfluoroalkyl substances in the environment: terminology, classification, and origins. Integr Environ Assess Manag. 2011;7(4):513-41.

17. Glynn A, Berger U, Bignert A, Ullah S, Aune M, Lignell S, Darnerud PO. Perfluorinated alkyl acids in blood serum from primiparous women in Sweden: serial sampling during pregnancy and nursing, and temporal trends 1996-2010. Environ Sci Technol. 2012;46(16):9071-9.

18. Bjerregaard-Olesen C, Bach CC, Long M, Ghisari M, Bossi R, Bech BH, Nohr EA, Henriksen TB, Olsen J, Bonefeld-Jorgensen EC. Time trends of perfluorinated alkyl acids in serum from Danish pregnant women 20082013. Environ Int. 2016;91:14-21.

19. Land M, de Wit CA, Bignert A, Cousins IT, Herzke D, Johansson JH, Martin $J W$. What is the effect of phasing out long-chain per- and polyfluoroalkyl substances on the concentrations of perfluoroalkyl acids and their precursors in the environment? A systematic review. Environmental Evidence. 2018;7:4

20. Grandjean P, Andersen EW, Budtz-Jorgensen E, Nielsen F, Molbak K, Weihe $P$, Heilmann C. Serum vaccine antibody concentrations in children exposed to perfluorinated compounds. Jama. 2012;307(4):391-7.

21. Douwes J, Pearce N. Asthma and the westernization 'package'. Int J Epidemiol. 2002;31(6):1098-102.

22. Goudarzi H, Miyashita C, Okada E, Kashino I, Kobayashi S, Chen CJ, Ito S, Araki A, Matsuura H, Ito YM, et al. Effects of prenatal exposure to perfluoroalkyl acids on prevalence ofallergic diseases among 4-year-old children. Environ Int. 2016:94:124-32.

23. Smit LA, Lenters $V$, Hoyer BB, Lindh $\mathrm{CH}$, Pedersen HS, Liermontova I, Jonsson BA, Piersma AH, Bonde JP, Toft G, et al. Prenatal exposure to environmental chemical contaminants and asthma and eczema in schoolage children. Allergy. 2015;70(6):653-60.

24. Timmermann CA, Budtz-Jorgensen E, Jensen TK, Osuna CE, Petersen MS, Steuerwald U, Nielsen F, Poulsen LK, Weihe P, Grandjean P. Association between perfluoroalkyl substance exposure and asthma and allergic disease in children as modified by MMR vaccination. J Immunotoxicol. 2017a;14(1):39-49.

25. Granum B, Haug LS, Namork E, Stolevik SB, Thomsen C, Aaberge IS, van Loveren H, Lovik M, Nygaard UC. Pre-natal exposure to perfluoroalkyl substances may be associated with altered vaccine antibody levels and immune-related health outcomes in early childhood. J Immunotoxicol. 2013;10(4):373-9

26. Impinen A, Nygaard UC, Lodrup Carlsen KC, Mowinckel P, Carlsen KH, Haug LS, Granum B. Prenatal exposure to perfluoralkyl substances (PFASs) associated with respiratory tract infections but not allergy- and asthmarelated health outcomes in childhood. Environ Res. 2018;160:518-23.

27. Kyhl HB, Jensen TK, Barington T, Buhl S, Norberg LA, Jorgensen JS, Jensen DF, Christesen HT, Lamont RF, Husby S. The Odense Child Cohort: aims, design, and cohort profile. Paediatr Perinat Epidemiol. 2015;29(3):250-8.

28. Vorkamp K, Nielsen F, Kyhl HB, Husby S, Nielsen LB, Barington T, Andersson AM, Jensen TK. Polybrominated diphenyl ethers and perfluoroalkyl substances in serum of pregnant women: levels, correlations, and potential health implications. Arch Environ Contam Toxicol. 2014;67(1):9-20.

29. Lind DV, Priskorn L, Lassen TH, Nielsen F, Kyhl HB, Kristensen DM, Christesen HT, Jorgensen JS, Grandjean P, Jensen TK. Prenatal exposure to perfluoroalkyl substances and anogenital distance at 3 months of age in a Danish mother-child cohort. Reproductive toxicology (Elmsford, NY). 2017;68:200-6.

30. Phase Three Manual, International study of asthma and allergies in childhood (ISAAC). http://isaac.auckland.ac.nz/story/methods/resources/ phasethreemanual.pdf.

31. Odense Child Cohort Questionnaire 6 (3-5 years). https://www. odenseboernekohorte.dk/for-deltagere/undersoegelser-og-spoergeskemaer/ spoergeskemaer.

32. Cave AJ, Atkinson LL. Asthma in preschool children: a review of the diagnostic challenges. J Am Board Fam Med. 2014;27(4):538-48.

33. Postma DS: Gender differences in asthma development and progression. Gend Med 2007, 4 Suppl B:S133-146.

34. Almqvist C, Worm M, Leynaert B. Impact of gender on asthma in childhood and adolescence: a GA2LEN review. Allergy. 2008;63(1):47-57.

35. Fei C, McLaughlin JK, Lipworth L, Olsen J. Prenatal exposure to PFOA and PFOS and risk of hospitalization for infectious diseases in early childhood. Environ Res. 2010;110(8):773-7.

36. Corsini E, Sangiovanni E, Avogadro A, Galbiati V, Viviani B, Marinovich M, Galli CL, Dell'Agli M, Germolec DR. In vitro characterization of the immunotoxic potential of several perfluorinated compounds (PFCs). Toxicol Appl Pharmacol. 2012;258(2):248-55.

37. Impinen A, Longnecker MP, Nygaard UC, London SJ, Ferguson KK, Haug LS, Granum B. Maternal levels of perfluoroalkyl substances (PFASs) during pregnancy and childhood allergy and asthma related outcomes and infections in the Norwegian mother and child (MoBa) cohort. Environ Int. 2019;124:462-72.

38. Weihe P, Kato K, Calafat AM, Nielsen F, Wanigatunga AA, Needham LL, Grandjean P. Serum concentrations of polyfluoroalkyl compounds in Faroese whale meat consumers. Environ Sci Technol. 2008:42(16):6291-5.

39. Lindh $\mathrm{CH}$, Rylander $\mathrm{L}$, Toft $\mathrm{G}$, Axmon A, Rignell-Hydbom A, Giwercman A, Pedersen HS, Goalczyk K, Ludwicki JK, Zvyezday V, et al. Blood serum concentrations of perfluorinated compounds in men from Greenlandic Inuit and European populations. Chemosphere. 2012;88(11):1269-75.

40. Abbas AL. LA: basic immunology. Philadelphia: Saunders Elsevir; 2011.

41. DeWitt JC, Peden-Adams MM, Keller JM, Germolec DR. Immunotoxicity of perfluorinated compounds: recent developments. Toxicol Pathol. 2012:40(2):300-11.

42. Fair PA, Driscoll E, Mollenhauer MA, Bradshaw SG, Yun SH, Kannan K, Bossart GD, Keil DE, Peden-Adams MM. Effects of environmentally-relevant levels of perfluorooctane sulfonate on clinical parameters and immunological functions in B6C3F1 mice. J Immunotoxicol. 2011:8(1):17-29.

43. Zheng L, Dong GH, Zhang YH, Liang ZF, Jin YH, He QC. Type 1 and type 2 cytokines imbalance in adult male C57BL/6 mice following a 7-day oral exposure to perfluorooctanesulfonate (PFOS). J Immunotoxicol. 2011;8(1):30-8.

44. Dong GH, Liu MM, Wang D, Zheng L, Liang ZF, Jin YH. Sub-chronic effect of perfluorooctanesulfonate (PFOS) on the balance of type 1 and type 2 cytokine in adult C57BL6 mice. Arch Toxicol. 2011;85(10):1235-44.

45. Corsini E, Luebke RW, Germolec DR, DeWitt JC. Perfluorinated compounds: emerging POPs with potential immunotoxicity. Toxicol Lett. 2014;230(2):263-70.

46. DeWitt JC, Blossom SJ, Schaider LA. Exposure to per-fluoroalkyl and polyfluoroalkyl substances leads to immunotoxicity: epidemiological and toxicological evidence. J Expo Sci Environ Epidemiol. 2019;29(2):148-56.

47. Keil DE, Mehlmann T, Butterworth L, Peden-Adams MM. Gestational exposure to perfluorooctane sulfonate suppresses immune function in B6C3F1 mice. Toxicol Sci. 2008;103(1):77-85.

48. Dalsager L, Christensen N, Husby S, Kyhl H, Nielsen F, Host A, Grandjean P, Jensen TK. Association between prenatal exposure to perfluorinated compounds and symptoms of infections at age 1-4years among 359 children in the Odense Child Cohort. Environ Int. 2016;96:58-64.

49. Olsen GW, Burris JM, Ehresman DJ, Froehlich JW, Seacat AM, Butenhoff JL, Zobel LR. Half-life of serum elimination of perfluorooctanesulfonate, perfluorohexanesulfonate, and perfluorooctanoate in retired fluorochemical production workers. Environ Health Perspect. 2007; 115(9):1298-305.

50. Laerum BN, Svanes C, Wentzel-Larsen T, Gulsvik A, Toren K, Norrman E, Gislason T, Janson C, Omenaas E. Young maternal age at delivery is associated with asthma in adult offspring. Respir Med. 2007;101(7):1431-8.

51. Thacher JD, Gruzieva O, Pershagen G, Neuman A, Wickman M, Kull I, Melen E, Bergstrom A. Pre- and postnatal exposure to parental smoking and allergic disease through adolescence. Pediatrics. 2014;134(3):428-34.

52. Asher MI, Keil U, Anderson HR, Beasley R, Crane J, Martinez F, Mitchell EA, Pearce N, Sibbald B, Stewart AW, et al. International study of 
asthma and allergies in childhood (ISAAC): rationale and methods. Eur Respir J. 1995;8(3):483-91.

53. Timmermann CA, Budtz-Jorgensen E, Petersen MS, Weihe P, Steuerwald U, Nielsen F, Jensen TK, Grandjean P. Shorter duration of breastfeeding at elevated exposures to perfluoroalkyl substances. Reprod Toxicol (Elmsford, NY). 2017b;68:164-70.

54. Romano ME, Xu Y, Calafat AM, Yolton K, Chen A, Webster GM, Eliot MN, Howard CR, Lanphear BP, Braun JM. Maternal serum perfluoroalkyl substances during pregnancy and duration of breastfeeding. Environ Res. 2016;149:239-46.

55. Mogensen UB, Grandjean P, Nielsen F, Weihe P, Budtz-Jorgensen E. Breastfeeding as an exposure pathway for Perfluorinated alkylates. Environ Sci Technol. 2015;49(17):10466-73.

56. Oddy WH, Holt PG, Sly PD, Read AW, Landau LI, Stanley FJ, Kendall GE, Burton PR. Association between breast feeding and asthma in 6 year old children: findings of a prospective birth cohort study. BMJ. 1999; 319(7213):815-9.

57. Greenland S, Pearl J, Robins JM. Causal diagrams for epidemiologic research. Epidemiology. 1999;10(1):37-48.

58. Dong GH, Tung KY, Tsai CH, Liu MM, Wang D, Liu W, Jin YH, Hsieh WS, Lee $Y L$, Chen PC. Serum polyfluoroalkyl concentrations, asthma outcomes, and immunological markers in a case-control study of Taiwanese children. Environ Health Perspect. 2013;121(4):507-13.

59. Zhou Y, Bao WW, Qian ZM, Dee Geiger S, Parrish KL, Yang BY, Lee YL, Dong GH. Perfluoroalkyl substance exposure and urine CC16 levels among asthmatics: A case-control study of children. Environ Res. 2017;159:158-63.

60. Humblet O, Diaz-Ramirez LG, Balmes JR, Pinney SM, Hiatt RA. Perfluoroalkyl chemicals and asthma among children 12-19 years of age: NHANES (19992008). Environ Health Perspect. 2014;122(10):1129-33.

\section{Publisher's Note}

Springer Nature remains neutral with regard to jurisdictional claims in published maps and institutional affiliations.

Ready to submit your research? Choose BMC and benefit from:

- fast, convenient online submission

- thorough peer review by experienced researchers in your field

- rapid publication on acceptance

- support for research data, including large and complex data types

- gold Open Access which fosters wider collaboration and increased citations

- maximum visibility for your research: over $100 \mathrm{M}$ website views per year

At $\mathrm{BMC}$, research is always in progress.

Learn more biomedcentral.com/submissions 